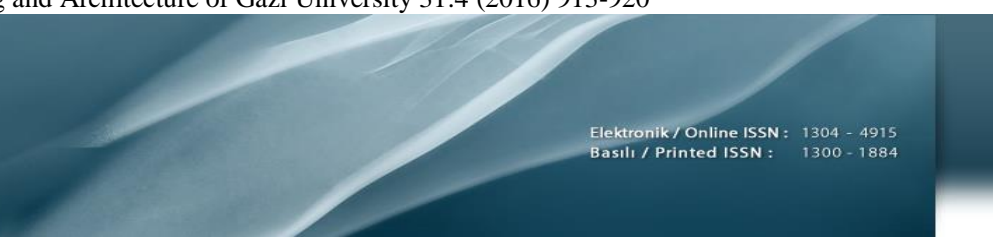

\title{
Hava sahası sektör tasarımı için model önerisi
}

\author{
Şaban Temizkan ${ }^{{ }^{*}}$, Aydın Sipahioğlu
}

${ }^{1}$ Kara Harp Okulu, Savunma Bilimleri Enstitüsü, Ankara, Türkiye

${ }^{2}$ Eskişehir Osmangazi Üniversitesi, Mühendislik ve Mimarlık Fakültesi, Eskişehir, Türkiye

Ö N E C I K A N L A R

- Dengeli hava sahası sektörleri

- Sektör tasarım modeli

- Dinamik iş yükü paylaşımı

Makale Bilgileri

Geliș: 26.05.2015

Kabul: 28.08.2015

DOI:

10.17341/gazimmfd.278446

Anahtar Kelimeler:

Hava sahası, sektörizasyon, araç rotalama

\section{ÖZET}

Teknolojinin havacılık alanında sağladığı yenilikler hava sahasının her geçen gün daha da kalabalık hale gelmesine sebep olmaktadır. Farklı amaçlar için üretilen farklı hava araçları hava sahasında yerini almaktadır. Bu yüzden hava trafiğini yönetmek daha da zor hale gelmektedir. Hava sahası sektör tasarımı, bir diğer deyişle hava sahası sorumluluk sahalarının belirlenmesi, hava trafik yönetim probleminin özel bir alanıdır. Hava trafiği, hava sahasının sektörlere bölünmesiyle yönetilmektedir ve hava trafik otoritesi, iş yükü ve kontrolör kapasitesi açısından yönetilebilir sektörler elde etmek üzere bölünecek sektör sayısına karar vermektedir. Bir sektördeki tüm hava araçları bir kontrolör ekibi tarafından yönetilir ve sektörlerin sınırları gerektiğinde değiştirilebilmektedir. Bu nedenle hava sahasının iş yükünü sektörlere mümkün olduğunca dengeli dağıtacak şekilde bölümlendirilmesi problemi ortaya çıkmaktadır. Bu çalışmada dengeli iş yüküne sahip hava sahası sektörleri elde edebilen araç rotalama problemi tabanlı bir matematiksel model önerilmektedir. Model, hava sahasının coğrafi referans sistemine göre dörtgenlere bölünmüş olmasına dayanmaktadır. Geliştirilen model ile Türkiye hava sahası için rassal olarak türetilmiş bir iş yükü senaryosu kullanılarak çözüm bulunmuş ve önerilen yöntemin hava sahası sektörizasyonunda başarıyla kullanılabileceği gösterilmiştir.

\section{A mathematical model suggestion for airspace sector design}

\section{H I G H L I G H T S}

- $\quad$ Balanced air space sectors

- Sector design model

- Dynamic workload share

Article Info

Received: 26.05 .2015

Accepted: 28.08.2015

DOI:

10.17341/gazimmfd.278446

Keywords:

Airspace,

sectorization,

vehicle routing

\section{ABSTRACT}

Airspace becomes crowded day by day because of the opportunities offered by technology in aviation. Different types of aircrafts which are made for different purposes take place in the sky. So, to manage air traffic is getting much more harder. Airspace sector design, in other words the determination of airspace area of responsibility is a special field of air traffic management problem. In order to obtain manageable sectors in terms of workload and controller capacity, air traffic authority decides the number of sectors to be divided. All aircrafts in a sector are controlled by a team of controllers and sector boundries can be changed when it is needed. Therefore partitioning problem of airspace accurs which distributes airspace workload to the sectors as balanced as possible. In this study a vehiclerouting problem based mathematical model is proposed to obtain airspace sectors having balanced workloads among the sectors. The model depends on discretization of the air space into quadrangles through geographical reference system. By developed model a solution is founded for Turkey's air space by using randomly derived workload scenario and it is shown that supposed method can be used successfully for air space sectorization.

\footnotetext{
*Sorumlu Yazar/Corresponding author: saban.temizkan@gmail.com / Tel: +90 5426599244
} 


\section{GİRIŞ̧ (INTRODUCTION)}

Hava sahası, teknolojinin havacılıkta her geçen gün sağladığı yenilikler sebebiyle daha da kalabalık hale gelmektedir. Değişik amaçlar için farklı hava araçları hava sahasında yerini almakta, bu yüzden hava sahasını yönetmek her geçen gün daha da zorlaşmaktadır. Kontrolörler hava sahasını sektörlere (sorumluluk sahalarına) bölerek yönetmektedirler. Her sektördeki hava araçları bir kontrolör ekibi tarafından kontrol edilmektedir. $\mathrm{Bu}$ yüzden hava sahası yönetim otoritesi kontrolör kapasitelerine göre hava sahasının bölüneceği sektör sayısına karar vermek istemektedir [1]. Hava sahası sektör optimizasyonu hava sahasını sektörlere bölme problemidir. Amacı sektörlerin sınırlarını değiştirerek aralarındaki iş yükünü dengelemektir [2, 3]. Bir sektörizasyon ile elde edilecek hava sahası sektörlerinin belirli özelliklere sahip olması gerekmektedir [4]. Her sektör; diğer sektörler ile dengeli iş yüküne sahip olmalı, yönetilebilir olmalı, geometrik olarak uygun olmalidir. Hava sahası sektörizasyonunda sektörler arasında iş yükü dengesinin sağlanması için sektörler arasındaki iş yükü farkının en küçüklenmesi gerekir. Bir sektörün iş yükünün nasıl belirlenmesi gerektiği ise ayrı bir problemdir. Bir sektörün yönetilebilir olması Şekil 1 ile açıklanabilir. Birbirine çok uzak hücreleri içeren sektörler diğer sektörlere göre dengeli iş yüküne sahip olsalar bile yönetilebilir değildirler. Yönetilebilir bir sektör monitörde kontrolör tarafından bir bütün olarak görüntülenebilir olmalıdır. Şekil 1'de hava sahası A ve B olmak üzere iki farklı şekilde 4 sektöre bölünmektedir. A bölünlenmesinde 2'inci ve 3'üncü sektörler yönetilebilir şekillere sahip değildirler. $\mathrm{Bu}$ sektörleri kontrolörün ekranında bir bütün olarak görüntülenmesi ve kontrol etmesi çok zordur. Diğer taraftan B bölümlemesindeki tüm sektörler daha yönetilebilir şekle sahiptirler. Bir sektör diğer bir sektörün içerisine doğru çok fazla ilerleme gösterirse o sektörlerin bir bütün olarak yönetilmesi zorlaşır vegeometrik uygunluğu bozulur. Şekil 2'deki sektörler kontrolör tarafindan bir bütün olarak ekranda görüntülenebilir şekle sahiptirler ancak 1, 3 ve 4'üncü sektörlerin bütünlüğü bozulmuş durumdadır. Hava sahası sektörizasyonu konusunda literartürde dikkate değer

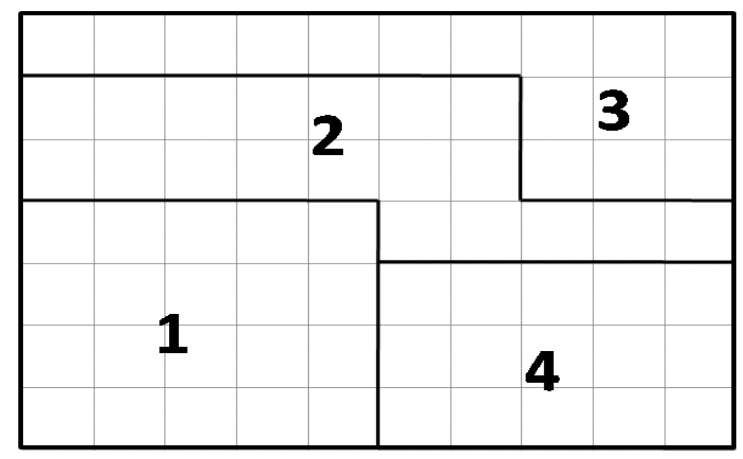

A birkaç çeşit çalışma bulunmaktadır. Bu çalışmalar Tang ve diğerleri tarafından Genetik Algoritma Tabanlı Voronoi Diyagramları, Uçuş Rotaları Kümleme Algoritması ve Karma Tamsayılı Programlama olarak 3 grupta sinıflandırılmaktadır [2].

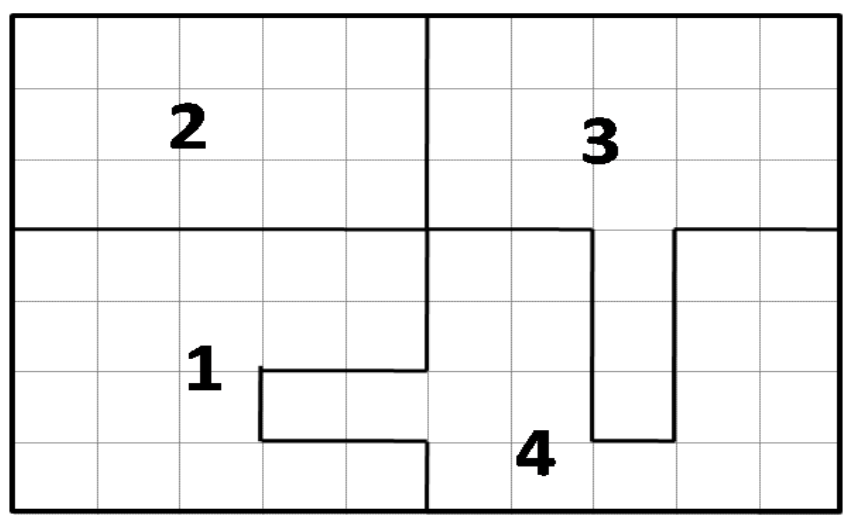

Şekil 2. Sektörlerin geometrik uygunluğu (Geometric suitability of sectors)

Uçuş Rotaları Kümeleme Algoritması uçuşları zamansal ve mekânsal olarak kümeleyerek hava sahasını sektörlere bölmektedir. $\mathrm{Bu}$ algoritmanın kullanılması için tüm uçuşların zamana göre konumsal verilerinin bilinmesi gerekmektedir. Bu algoritmanın zayıf tarafi da bu bilgileri elde etmenin zorluğudur [5]. Genetik Algoritma Tabanlı Voronoi Diyagramı metodu iki aşamadan oluşmaktadır. Birinci aşamada hava sahası Voronoi Diyagramları kullanılarak hava yollarının kesişiminden oluşan üçgensel alanlara bölünmektedir. İkinci aşamada genetik algoritma ile bu parçalar birleştirilerek hava sahası sektörleri oluşturulmaktadır. $\mathrm{Bu}$ yöntemde iş yükünü hava yolları üzerindeki uçak sayıları oluşturmaktadır. [6-9]. Karma Tamsayılı Programlama yöntemlerinde ise hava sahası eşit büyüklükteki çokgenlere bölünmektedir. Izgara tabanlı yöntemler olarak da bilinmektedir. Her çokgen bir hücre olarak adlandırılmakta ve bu hücreler merkez olarak belirlenen yerlere atanarak sektörler oluşturulmaktadır [1012]. Tang'in sinıflandırmasının yanında hava sahası sektörizasyonu konusundaki çözüm metotları iş yükünün

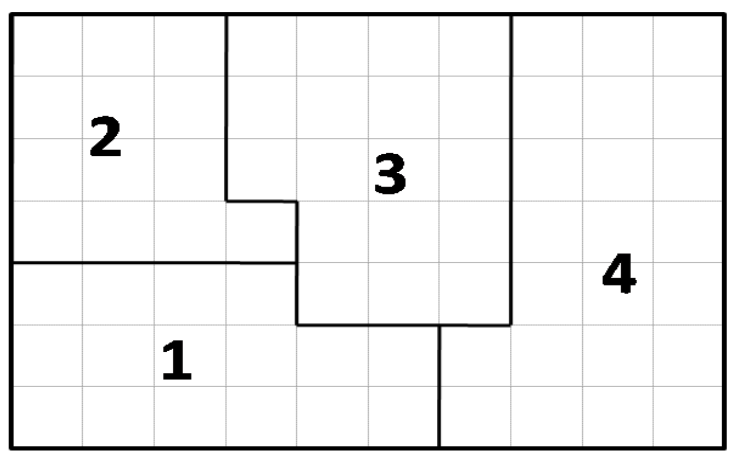

B

Şekil 1. Sektörlerin yönetilebilirliği (Managebility of sectors) 
tanımlanmasına göre de sinıflandırılabilir. Hava sahasındaki iş yükü tanımlanırken iki farklı yaklaşım kullanılmaktadır. Birinci yaklaşım hava yollarından oluşan ağdaki rotaları kullanan uçak sayısını iş yükü olarak tanımlamaktadır [5-9]. İkinci yaklaşım ise hava sahasının çokgenlere bölünmüş olmasına dayanmaktadır [10-13]. Herbir alan içerisinde bulunan hava araçlarının sayısı iş yükünü oluşturmaktadır. Sadece hava yollarını kullanarak seyir eden uçakları kontrol etmek hava sahasının yönetildiği anlamına gelmediğinden, birinci yaklaşımı kullanarak iş yükünü belirleyen ve hava sahası sektörizasyonu yapan yöntemlerin yeterli sayılamayacağını söylemek gerekir. Sektör iş yükü, sektör içerisinde bulunan ve hava yolu rotalarını kullanmadan seyir eden tüm hava araçlarının da iş yükünü içermektedir. Bu sebeple uçuş rotaları kümeleme algoritmasının ve genetik algoritma tabanlı Voronoi diyagramı metodunun sunduğu çözümler sadece hava yollarını kullanan trafikler için sektörler oluşturmaktadır, bu da hava sahası yönetimi için uygun değildir. $\mathrm{Bu}$ çalışmada hava sahasını sektörlere bölmek üzere yukarıda değinilmiş olan ikinci yaklaşıma dayanan, araç rotalama probleminden uyarlanmış bir matematiksel model önerilmektedir. Araç rotalama problemi (ARP) (Vehicle routing problem-VRP) sınırlı kapasiteleri olan araçların tanımlanmış düğümleri (müşterileri) toplamda en az yolu kat edecek şekilde ziyaret etmleri için izlemeleri gereken rotaların belirlenmesi problemidir. Yöneylem araştırması literatüründe yaygın olarak çalışılmış bir konudur. Fakat ARP'nin hava sahası sektörizasyon problemi için bir uygulaması henüz yapılmamıştır. Bu çalışmada ilk kez ARP'nin sektörizasyon problemi için nasıl uygulanabileceği gösterilmektedir. Bu amaçla bilinen ARP modelindeki düğüm, değişken ve parametre tanımlarının sektörizasyon probleminde nasıl olması gerektiği açıklanmış ve Türkiye hava sahası için ARP temelli sektörizasyon modeli geliştirlmiştir. Modelde Türk hava sahası 55 hücre ile temsil edilmektedir. Hücrelerin iş yükü değerlerinin ülkenin içinde bulunduğu uluslararası ilişkilere bağlı olarak nasıl hesaplanması gerektiğine dair bir çalışma yapılmıştır. Ancak bu makalenin esas amacı ARP ile sektörizasyon probleminin çözüebileceğini göstermek olduğu için hücrelerin iş yükü değerleri hesabına yer verilmemiş, fakat elde edilen iş yükü değerleri modelde parametre olarak kullanılmıştır. $\mathrm{Bu}$ amaçla çalışmanın 2'inci bölümde geliştirilmiş olan matematiksel model açılanmakta, 3'üncü bölümde Türk hava sahası için yapılan uygulama sonucu elde edilen sektörlerverilmekte ve 4'üncü bölümde çalışmanın sonuçları değerlendirilmektedir.

\section{GELISTTIRİLEN MATEMATIKSEL MODEL (DEVELOPED MATHEMATICAL MODEL)}

Geliştirilen matematiksel model aslında bilinen tek depolu, kapalı turlu araç rotalama problemi (ARP) modelinin yeniden yorumlanması, değişken ve parametrelere yeni anlamlar yüklenmesiyle elde edilmektedir. $\mathrm{Bu}$ nedenle izleyen kesimlerde önce araç rotalama problemi daha sonra ele alınan probleme dair model açıklanmıştır.

\subsection{Araç Rotalama Problemi (Vehicle Routing Problem)}

Araç rotalama problemi (ARP) 50 yıla yakın bir zamandır üzerinde çalışılan ve pek çok türü olan kombinatoryal eniyileme problemidir. ARP ilk olarak Dantzig ve Ramser tarafından 1959 yılında tanımlanmıştır. İzleyen zaman içinde matematiksel modelde özelikle alt tur engelleme kısıtlarının iyileştirilmesine çalışılmıştır. Ayrıca ARP'nin pek çok farklı türü de tanımlanmıştır. Problemin kombinatoryel olması nedeniyle sezgisel ve meta sezgisel algoritmalarla da çözümü araştırılmıştır. En bilinen sezgisel algoritmalardan biri Clarke ve Wright tarafindan 1964 yılında geliştirilen kazanım (Savings) algoritmasıdır. Daha sonra ARP'nin her değişik türü için farklı pek çok yöntem önerilmiştir [14]. Bu ilgi halen de devam etmektedir. Araç rotalama bir serim problemi olarak tanımlanmaktadır. $\mathrm{G}=(\mathrm{V}, \mathrm{A})$ tam bağlı bir serim olduğu varsayıldığında, $\mathrm{V}=\{1, . ., \mathrm{n}\}$ düğümler kümesini ve $\mathrm{A}$ ayritlar kümesini oluşturmaktadır. $\mathrm{j}=1, . ., \mathrm{n}$ düğümleri, talepleri $d_{j}$ olarak gösterilen ve talep değerleri negatif olmayan müşterilere karşılık gelmektedir. 0'ıncı veya 1'nci düğüm genellikle depoyu temsil etmek için kullanılır. Negatif olmayan $c_{i j}$ değeri ise her bir $(i, j) \in A$ ayrıtı ile ilişkilidir ve genellikle $\mathrm{i}$ düğümünden $\mathrm{j}$ düğümüne ulaşım maliyetini veya mesafesini gösterir. Her $(\mathrm{i}, \mathrm{j}) \in \mathrm{V}$ için $c_{i j}=c_{j i}$ sağlanıyorsa problem simetrik, aksi takdirde asimetrik araç rotalama problemi olarak adlandırılmaktır [15]. Bunun yanı sıra eğer bütün düğümler arasında doğrudan karşılıklı bağlantı varsa serim tam bağlı (complete) yoksa seyrek bağlı (sparse) olarak nitelendirilir. Ayrıca araçların çıkış yaparak döndüğü tek bir merkez varsa probleme tek depolu (single depot), çok merkez varsa çok depolu (multi depot) ARP denir. Çok depolu problemde araçların aynı merkeze dönme zorunluluğu olmayabilir. Bu durumda problem açık turlu ARP olarak isimlendirlir. Diğer durumlarda ise kapalı turlu ARP olur. Tek deoplu problem zorunlu olarak kapalı turlu bir problem anlamına gelir. Araç filosunun homojen ya da heterojen olması da problemi doğrudan etkiler. Genellikle araçların homojen olduğu varsayılır. $\mathrm{Bu}$ çalışmada tek depolu (dolayısıyla kapalı turlu), homojen filolu ve tam bağlı ARP modeli hava sahası sektörizasyonu problemine uyarlanmaktadir.

ARP modeli için değişken ve parametreler şöyle verilebilir:

Xij: i'den j'ye geçiş varsa 1 , cij: $\mathrm{i}$ ile $\mathrm{j}$ arasındaki mesafe ; Qi: i. düğümün talebi;

olmak üzere matematiksel model:

Amaç fonksiyonu

$\operatorname{Enk} \sum_{i=1}^{n} \sum_{j=1}^{n} d_{i j} * x_{i j}$

Kisitlar

$\sum_{j}^{n} x_{1 j}=m$ 
$\sum_{i}^{n} x_{i 1}=m$

$\sum_{j}^{n} x_{i j}=1 \quad \forall i \in\{2, \ldots, n\}$

$\sum_{i}^{n} x_{i j}=1 \quad \forall j \in\{2, \ldots, n\}$

$u_{i}-u_{j}+C * x_{i j} \leq C-q_{j} \quad i \neq j \neq 1$

Bu modelde amaç fonksiyonu Eş. 1, toplam katedilen yolun enküçüklenmesidir. Eş. 2 ve Eş. 3 kısıtları, başlangıç düğümden (depodan) $\mathrm{m}$ tane aracın çıkıp, $\mathrm{m}$ tane aracın geri dönmesini garantiler. Eş. 4 ve Eş. 5 kısıtları ise depo hariç diğer bütün düğümlere sadece bir kez uğranmasını garantiler. Eş. 6 kısıtı alt tur engelleme kısıtıdır. Hem alt tur oluşumunu engeller, hem de araç kapasitesinin aşılmamasını garantiler. Sonraki y1llarda alt tur engelleme kısıtları için daha gelișkin formülasyonlar önerilmiștir. Çalışmada geliştirilen modelde de söz konusu gelişkin formülasyon kullanılmıştır.

$\mathrm{Bu}$ modelde serimdeki ayrıt sayısının 2 katı kadar 0-1 tamsayılı x değişkeni ve düğüm sayısı kadar reel u değişkeni olur. Tam bağlı bir serimde ayrıt sayısı $n *(n-1) / 2$ kadardır. Dolayısıyla $n^{*}(n-1)$ tane $x$ değişkeni, $n$ tane $u$ değişkeni vardır. Öte yandan her düğüm için giriş ve çıkış kısıtları yazılacağı için $2 * \mathrm{n}$ tane kısıt, alt tur engelleme kısıtları da başlangıç düğümü içermeyecek ayritlar için 2 yönde de yazılacağından $(\mathrm{n}-1)^{*}(\mathrm{n}-2)$ tane olacaktır. Sonuçta modelde $n^{2}-n+2$ tane kisit vardir.

\subsection{Hava Sahası Sektör Tasarımı Modeli (Airspace Sector Design Model)}

Geliştirilen modelde araç rotalarının kapalı olması gerektiği, araçların homojen olduğu ve serimin de simetrik olması gerektiği belirlenmiştir. Sektör kapasiteleri araç kapasitesini (C), araç rotaları ise sektörleri oluşturacaktır. Rotalar yapay olarak tanımlanmış 1 numaralı düğümden başlayarak yine 1 numaralı düğümde bitecektir. Dolayısıyla diğer bütün düğümlerin 1 numaralı düğüm ile doğrudan bağlantısı olduğu kabul edilir. Tasarıma ait ayrıntılı açıklamalar aşağıdaki bölümlerde anlatılmaktadır.

\subsection{Hava Sahasının Tasarımı (Design of Airspace)}

İzlenmesi istenen hava sahası, coğrafi koordinat sistemine $\mathrm{m}^{\mathrm{o}}$ 'lik enlem ve $\mathrm{n}^{\mathrm{o}}$ 'lik boylamın içerinde kalan alandan oluşmaktadır. Bu enlem ve boylamların kesişiminden $m * n$ adet hücre elde edilmektedir. Her bir hücrenin dizilişi Şekil 3 'de gösterilmektedir.

Problem araç rotalama olarak düşünüldüğünde her bir hücre, bir düğümü temsil eder. Her bir hücrenin kenar komşulukları ise o düğümden gidilebilecek düğümleri oluşturur. Dolayısıyla her bir düğümden sadece dört düğüme geçiş yapılabilir. Eğer bir i hücresi ile bir j hücresi arasında komşuluk varsa aralarındaki uzaklık 1, yoksa 0 olarak alınacaktır.

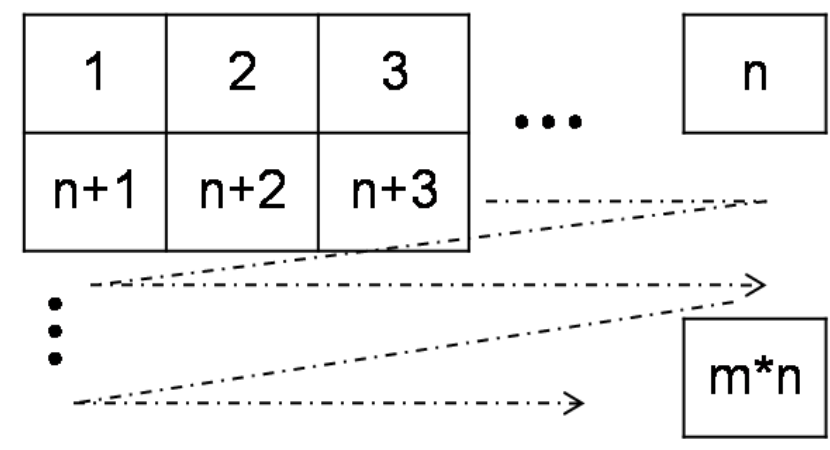

Şekil 3. Hücrelerin dizilişi (The aligment of cells)

\subsection{Sektör Kapasiteleri (Sector Capacities)}

Matematiksel modelde her bir sektör bir aracı temsil etmektedir. Hava sahasının toplam iş yükünün sektörlere eşit paylaştırılması hedeflendiğinden araçlar homojen kapasiteye sahip olmalıdır. Araç kapasiteleri hesaplanırken hava sahasının toplam iş yükünün sektörlere bölünmesi, kapasite kısıtını çok sıkı hale getirmektedir. Bu durumun problemi çözümsüz hale getirmesini engellemek için araç kapasiteleriøgevşetme parametresi ile gevşetilmektedir. Bu nedenle sektör kapasiteleri şöyle belirlenir.

SKAP: Sektör kapasitesi olmak üzere;

$S K A P=\frac{\sum_{i=1}^{m * n} q_{i}}{S} *(1+\propto)$

\subsection{Matematiksel Model (Mathematical Model)}

Modelde kullanılan semboller, parametreler ve karar değişkenleri aşağıdaki gibi tanımlanmaktadır.

İndisler ve Kümeler

i : hücrelerin (düğümlerin) indisi i $\in\{1, \ldots, m * n\}$

j : : komșu hücrelerin (düğümlerin) indisi

$\mathrm{j} \in\{1, \ldots, m * n\}$

$\mathrm{m}$ : enlem sayıs1

$\mathrm{n} \quad$ : boylam sayıs

Parametreler

$c_{\mathrm{ij}} \quad:\left\{\begin{array}{l}1 \\ 0\end{array}\right.$ Eğer i hücresi ile j hücresi arasında

komşuluk var ise 1 , diğer durumlarda 0 .

$\mathrm{q}_{\mathrm{i}} \quad$ : i hücresinin iş yükü

S : Sektör sayısı

$\propto \quad$ : Araç kapasitesi gevşetme parametresi

SKAP : Sektör kapasitesi

Karar değişkenleri

$\mathrm{x}_{\mathrm{ij}}:\left\{\begin{array}{l}1 \\ 0\end{array}\right.$ Eğer i hücresinden $\mathrm{j}$ hücresine geçiliyorsa 1, diğer durumlarda 0 . 
Matematiksel model:

Amaç fonksiyonu

$E n k z=\sum_{i=1}^{m * n} \sum_{j=1}^{m * n} x_{i j}$

Amaç fonksiyonu toplam mesafenin en küçüklenmesidir. $\mathrm{c}_{\mathrm{ij}}$ uzaklık matrisinde uzaklık değerleri komşuluk olduğundan 1 değerini almakta karar değişkeni $x_{i j}$ 'nin değer alması durumunda 1 ile çapılması işlem sonucunu değiştirmemektedir. Dolayısıyla amaç fonksiyonunda sadece değer alan karar değișkenlerinin toplamını en küçüklemek toplammesafeyi enküçüklemek anlamına gelmektedir, ayrıca işlem sayısını da azaltmaktadır.

Kisitlar

$\sum_{j>1}^{m * n} x_{1 j}=S$

$\sum_{i>1}^{m * n} x_{i 1}=S$

Problemdeki sektör sayısı (S) modelde kullanılacak araç sayısına karşı gelmektedir. Kapalı turlu olarak rotalanmış olan modelde tüm araçların birinci düğümden çıkıp yine birinci düğüme dönmesi gerekir. Dolayısıyla tüm düğümlerden birinci düğüme ve birinci düğümden tüm düğümlere geçiş olduğu varsayılmaktadır. Bu varsayımla Eş. 9 ve Eş. $10 \mathrm{~S}$ tane aracın birinci düğümden (merkezden) çıkışını ve yine birinci düğüme dönüşünü garantilemektedir.

$\sum_{j>1 j \neq i}^{m * n} c_{i j} * x_{i j}=1 \quad \forall i \in\{2, \ldots, m * n\}$

$\sum_{i>1 i \neq j}^{m * n} c_{i j} * x_{i j}=1 \quad \forall j \in\{2, \ldots, m * n\}$

Eș. 11 her düğümden mutlaka komşularından birine çıkmayı, Eş. 12 ise her düğüme mutlaka komşularından birinden gelmeyi sağlamaktadır. Böylece her düğüme $1 \mathrm{kez}$ uğranması garantilenmektedir.

$u_{i}-u_{j}+\left(S K A P * x_{i j}\right)+\left(S K A P-q_{i}-q_{j}\right) * x_{j i} \leq S K A P-q_{j}$

$\forall i \in\{2, \ldots, m * n\} \forall j \in\{2, \ldots, m * n\}$

$u_{i} \leq S K A P-\left[S K A P-\left(\max _{j \neq i}\left(q_{j}-q_{i}\right)\right] * x_{1 i}-\sum_{j}^{n} q_{j} * x_{i j}\right.$

$i \in\{2, \ldots, m * n\}$

Eş. 13 ve Eş. 14 ise Kara vd. tarafindan 2004'de önerilen alt tur engelleme kısıtlarıdır [16]. Eş. 13 tur devamlılığını ve sektör (araç) kapasitelerinin aşılmamasını sağlayan kısıttır. Eş. 8 ise herhangi bir i düğümden en büyük $q_{j}$ değerine sahip komşu j düğümüne geçişi sağlamaktadır. Model, temelde bir araç rotalama modeli olduğu için, model büyüklüğü de daha önce verilen ARP modeli ile aynıdır. Bu modelin en önemli özelliği eniyi çözümde bulunacak amaç fonksiyonu değerinin önceden biliniyor olmasıdır. Çünkü m*n düğümlü bir serimde bütün ayrıtların birbirleri arasındaki mesafe 1 olarak alındığında $S$ tane aracın olması halinde her düğüme mutlaka bir kez uğranma zorunluluğu ve araç turlarının birbirleriyle kesişmemesi nedeniyle, en kısa mesafe $m^{*} n+s-1$ çıkar. Bu nedenle en iyi çözüm değeri $\mathrm{m}^{*} \mathrm{n}+\mathrm{s}-1$ 'dir. Yani aslında problem çözülmeden önce eniyi çözüme ait amaç fonksiyonu değeri bilinmekte ama araçların kapasitelerini aşmadan hangi düğümlere uğrayacağı bilinmemektedir. Ancak en iyi çözüm bulunduğunda araçların uğradığı düğümler ise hava sahasının sektörlerini verecektir. Öte yandan GAMS gibi bir yazılım kullanıldığında amaç fonksiyonu değeri çözüme başlanmadan önce bir üst sınır değeri (cut off) olarak girilebilir. Böylece yazılım verilen üst sınır değerinden daha kötü olan bütün çözümleri hızla eleyecek, bulduğu ilk uygun çözüm ise problemin eniyi çözümü olacaktır. Eniyi çözümde sektörler arasındaki yük değişkenliği de en fazla $\alpha$ kadar olacaktır. Böylece araç rotalama modeli kullanılarak birbirleri arasındaki iş yükü farkı en çok $\alpha$ kadar olan hava sahası sektörlerinin belirlenmesi mümkün hale gelmektedir.

İzleyen bölümde geliştirilen modelin başarısı Türkiye hava sahasını temsil edecek şekilde türetilen örnek problem üzerinde denenmiş ve elde edilen sonuçlar tartışılmıştır.

\subsection{Uygulamaya Yönelik Analizlerinin Yapılması (Analyzing for Implementation)}

\subsubsection{Sektör sayısının çözüm süresine etkileri} (The effects of the number of sectors to the solution time)

Hava sahasının bölüneceği sektör sayısı karar vericilerin talepleri ile belirlenmektedir. Hava sahası genellikle çok dinamik yapıdır dolayısıyla yoğunluğu ve iş yükü gün içerisinde bile çok değişkendir. Mevcut hava sahası kontrol sektörlerinde, toplam iş yükünün mevcut sektör sayısı ile yönetilemeyeceği durumlarda, diğer bir deyişle tüm/bazı sektörlerde kontrolörlerin kapasitelerinin üzerinde iş yükü oluşması durumunda karar vericiler sektör sayısını arttırmayı talep edebilmektedirler. Bunun aksine mevcut sektörlerde atıl işgücü ile çalışmak yerine karar vericiler sektör sayılarını azaltmayı talep edebilmektedirler.

Sektör sayısının değişiminin çözüm süresine olacak etkilerini incelemek üzere 11X5 hücreden oluşan bir hava sahası tasarlanmış, tasarlanan bu hava sahasında hücrelerin verileri rastgele üretilerek hava sahası 3, 4, 5 sektöre bölünmüştür. Gevşetme Parametresi $(\alpha) \% 5$ olarak alınmıştır. Çalışmaya ait sonuçlar Tablo 1'deki gibidir.

Tablo 1. Sektör sayısına göre çözüm süreleri (Solution times by the number of sectors)

\begin{tabular}{ll}
\hline Sektör Sayıs & Süre \\
\hline 3 Sektör & 2 dakika 39 saniye \\
4 Sektör & 6 dakika 9 saniye \\
5 Sektör & 1 saat 59 dakika 25 Saniye \\
\hline
\end{tabular}

Tablo 1 incelendiğinde sektör sayısının artmasının çözüm süresinin uzamasına sebep olduğu açıkça görülmektedir. 
2.6.2. Gevşetme parametresi ( $\alpha$ )'nın çözüm süresine etkileri (The effects of the relaxation parameter $(\alpha)$ to the solution time)

Gevşetme parametresi ile ilgi analizleri yapmak üzere 11X5 hücreden oluşan bir hava sahası tasarlanmış, sektör sayısı 3 kabul edilmiş ve gevşetme parametresi $\% 1, \% 3$ ve $\% 5$ olarak kabul ederek çözümler elde edilmiştir. Çözüm sürelerine ait sonuçlar Tablo 2'de gösterilmektedir.

Tablo 2. Gevşetme parametresi değişiminin çözüm sürelerine etkileri

(The effects of variation of relaxation parameter)

\begin{tabular}{ll}
\hline Gevşetme Parametresi $(\alpha)$ & Süre \\
\hline$\% 1$ & 48 dakika 38 saniye \\
$\% 3$ & 9 dakika 9 saniye \\
$\% 5$ & 3 dakika 4 saniye \\
\hline
\end{tabular}

Tablo 2 incelendiğinde gevşetme parametresinin büyümesinin problemin çözüm süresini kısalttığ1 görülmektedir.

\subsubsection{Veri setinin çözüm süresine etkileri}

(The effects of the data set to the solution time)

Çalışmada kullanılan veri setinin problemin çözüm süresine etkilerini gözlemlemek üzere 11X5 hücreden oluşan 3 adet hava sahası tasarlanmıştır. Her hava sahası için hücrelerin iş yüklerine yönelik veriler rassal olarak üretilmiştir. Sektör sayısı 3 ve gevşetme parametresi $\% 5$ alınmıştır. Çözüm süresine etkileri gösteren sonuçlar Tablo 3'de gösterilmektedir.

Tablo 3. Veri seti değişiminin çözüm süresine etkileri (The effects of variation of data set)

\begin{tabular}{ll}
\hline Veri Seti & Süre \\
\hline Veri Seti 1 & 26 saniye \\
Veri Seti 2 & 3 dakika 4 saniye \\
Veri Seti 3 & 2 dakika 39 saniye \\
\hline
\end{tabular}

Tablo 3 incelendiğinde veri setinin değişmesinin çözüm süresi üzerinde ciddi bir etkisi olmadığı görülmektedir.

\section{TÜRKIYYE HAVA SAHASI İÇIN BİR UYGULAMA (AN APPLICATION FOR TURKISH AIRSPACE)}

Geliştirilen modelin geçerliliğini sınamak üzere Türkiyeiçin örnek bir test problemi üretilmiştir. Türkiye'nin hava sahası yönetimi yaptığ 1 saha $24^{\circ}-46^{\circ}$ doğu meridyenleri ve $34^{\circ}-44^{\circ}$ kuzey paralelleri arasında kalan alandan oluştuğu varsayılmıştır. Bahse konu alanda her $2^{\circ}$ 'lik meridyen ve paralelin kesişiminden 11 X5'lik bir alan elde edilmiştir. Elbette ki hava sahasını daha küçük veya daha büyük alanlara ayırmak mümkündür. Örneğin 1 derecelik meridyen ve paralel kesişimi düşünülürse ortaya daha fazla alan çıacaktır ve daha hassas bir bölümlendirme yapılabilir. Ancak bu durumda incelenecek daha fazla alan olduğu için çözüm süresi uzayacaktır. Gözlemlere göre 2 derecelik meridyen ve paralel kesişiminin Türk hava sahası sektörizasyonunda yeterli olduğu anlaşıldığı için bu değer tercih edilmiştir. Elde edilen hücrelerin iş yükü değerleri ise ülkenin içinde bulunduğu uluslararası ilişkilere bağlı olarak yapılan bir puanlama ve Analitik Hiyerarşi yöntemi (AHP) uygulaması sonucunda elde edilmiştir. Öyle ki hava sahasını izlemede öne çıkan kriterler belirlenerek bunların ağırlıkları karar vericiler tarafından ikili karşılaştırmalar ile belirlenmiş ve AHP uygulamasıyla ağırlıkları hesaplanmıştır. Olası bir senaryoda karşılaşılan risklere puanlar verilerek ve hesaplanan ağırlıklarla çarpılarak her bir hücre için işyükü değeri belirlenmiştir. Bu çalışmada her hücrenin iş yükü değeri puan olarak 4-24 aralığında elde edilmiştir. Şekil 4'de hücrelerin dizilişi ve elde edilen iş yükü değerleri gösterilmektedir. Hava sahasının 5 sektöre bölünmesi planlanmış ve gevşetme parametresi \%5 olarak kabul edilmiştir. 1'inci eşitlik kullanılarak örnek problem için sektör kapasiteleri 115,55 bulunmuştur. Matematiksel model GAMS yazılımının 23.5.1 versiyonunda kodlanarak CPLEX çözücüsü ile çözülmüştür. Amaç fonksiyonu değeri (55) yazılıma üst sınır değer olarak girilmiştir. Bu koşullar altında yazılım, test probleminin eniyi çözümünü $6 \mathrm{dk} .15$ saniyede elde etmiştir. Şekil 5'te elde edilen çözüm görülmektedir. Sektörlerin iş yükleri sırasıyla 111,09, 110,36, 113,53, 107,88, 107,38 olarak bulunmuştur. Test probleminden elde edilen sektörlerin hava sahasındaki görüntüsü Şekil 6'da gösterilmektedir. Önerilen modelle test probleminde elde edilen sektörlerin yönetilebilir olduğu ve geometrik olarak uygun olduğu Şekil 6'dan görülmektedir. $\mathrm{Bu}$ test probleminde elde edilen sektörler daha önce sözü edilmiş olan koşulları da sağlamaktadır. Ayrıca sektörler arasındaki iş yükü dağılım farkı en fazla $\% 5$ olacak şekilde dengelenme sağlanmıştır.

Burada dikkat edilmesi gereken önemli bir konu problemin bir tek eniyi çözümünün olmayacağı gerçeğidir. Çünkü bütün hücreler arasındaki mesafeler 1 olarak kabul edilmiştir. Dolayısıyla aynı amaç fonksiyonu değerini verecek başka çözümler, yani alternatif çözümler vardır. Bunun yararı, çözüm sonucu ortaya çıkan sektörizasyonun karar verici tarafindan beğenilmediği durumda bir başka çözümün daha bulunabilecek olmasıdır. Özellikle elde edilen sektörizasyonun yönetilebilir olmadığ1 düşünüldüğünde diğer çözümlerin araştırılmasıyla yeni sektörizasyon yapısı elde edilebilir.

Hava sahasının daha küçük alanlara bölünmesi, hücre sayısını yani araç rotalama problemindeki düğüm sayısını arttıracağı için çözüm süresini doğrudan etkiler. Kısacası bölünecek hava sahası ne kadar büyükse ve ne kadar küçük hücrelere ayrılıyorsa o kadar çok düğüm çıkacak demektir. Bilindiği gibi ARP, NP-zor sınıfındadır ve büyük boyutlu problemler için makul zamanda çözüm bulunamayabilir. Oysa bu problemin kısa sürede çözülmesi tercih edilir. Bu durumda ARP için geliştirilmiş klasik ve meta sezgisel yöntemlerin kullanılması mümkündür. ARP için geliştirilmiş ve eniyi çözümün \%1-2 civarında sonuç vereceği bilinen sezgiseller kullanılarak problemin kısa sürede çözülmesi mümkündür. 


\begin{tabular}{|c|c|c|c|c|c|c|c|c|c|c|c|}
\cline { 2 - 12 } 1 & 7,84 & 8,29 & 4,27 & 4 & 4 & 4,8 & 4 & 4,54 & 5,17 & 6,34 & 4,52 \\
\cline { 2 - 13 } 2 & 11,76 & 6,85 & 7,86 & 5,8 & 7 & 5,92 & 4 & 4,8 & 6,08 & 6,44 & 8,31 \\
\cline { 2 - 13 } 3 & 13 & 14,57 & 9,61 & 9,98 & 9,52 & 7,32 & 7,12 & 5,82 & 12,66 & 14,88 & 10,34 \\
\cline { 2 - 13 } 4 & 12,24 & 15,98 & 12,54 & 15,57 & 8,82 & 18,12 & 21,28 & 21,35 & 22,68 & 18,38 & 9,22 \\
\cline { 2 - 12 } & 10,88 & 9,68 & 6,15 & 5,96 & 22,41 & 23,96 & 13,08 & 13,08 & 11,37 & 5,04 & 5,04 \\
\hline
\end{tabular}

Şekil 4. Test problemi iş yükleri (The workload of test problem)

\begin{tabular}{|c|c|c|c|c|c|c|c|c|c|c|c|}
\hline 1 & 7,84 & 8,29 & 4,27 & 4 & 4 & 4,8 & 4 & 4,54 & 5,17 & 6,34 & 4,52 \\
\hline 2 & 11,76 & 6,85 & 7,86 & 5,8 & 72 & 5,92 & 4 & 4,8 & 6,08 & 6,44 C & 8,31 \\
\hline 3 & 13 & 14,57 & 9,61 & 9,98 & 9,52 & 7,32 & 7,12 & 5,82 & 12,66 & 14,88 & 10,34 \\
\hline 4 & 12,24 & 15,98 & 12,54 & 15,57 & $8,8 \mathbf{9}$ & 18,12 & 21,28 & 21,35 & 22,68 & 18,38 & 9,22 \\
\hline 5 & 10,88 & 9,68 & 6,15 & 5,96 & 22,41 & 23,96 & 13,08 & 13,08 & 11,37 & 5,04 & 5,04 \\
\hline & 1 & 2 & 3 & 4 & 5 & 6 & 7 & 8 & 9 & 10 & 11 \\
\hline
\end{tabular}

Şekil 5. Test problemi çözüm (The solution of test problem)

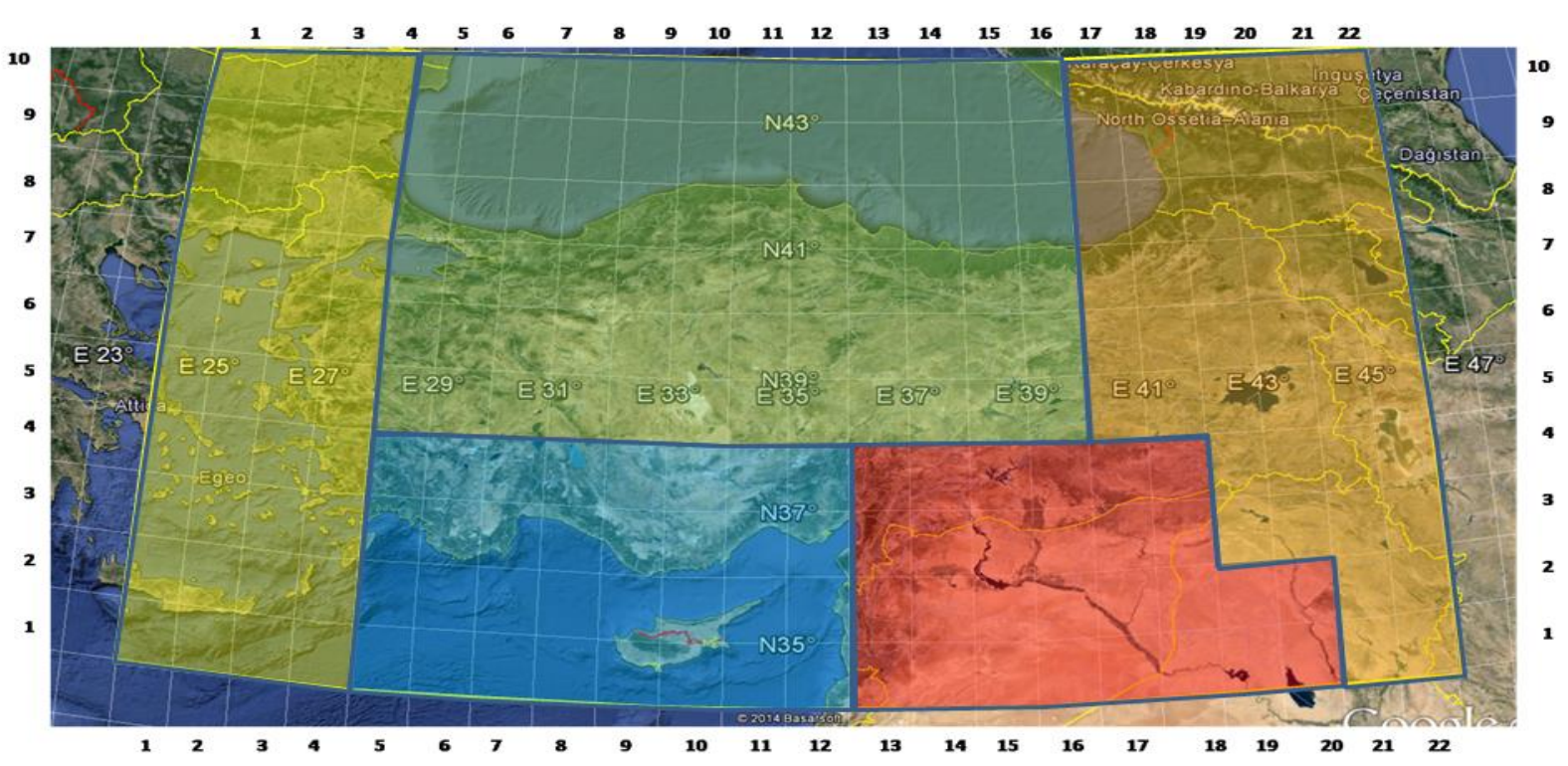

Şekil 6. Çözümün Türkiye haritası üzerindeki görüntüsü (The display of solution on Turkey map)

\section{SONUÇLAR (CONCLUSIONS)}

Bu çalışmada hava sahası sektör tasarımı için araç rotalama probleminden uyarlanarak bir matematiksel model önerilmiştir. Sektörizasyon problemi ilk defa bir araç rotalama problemi gibi tanımlandığı için önemlidir. Geliştirilen matematiksel model karar vericinin özel isteklerine cevap verecek şekilde değiştirilebileceği için esnektir. Örneğin Karadeniz ve Akdeniz kıyılarının aynı sektör tarafindan izlenmemesi istendiğinde bunu sağlayacak ek bir kısıt yazmakla yeni çözüm elde edilebilecek durumdadır. Modelin en önemli özelliği yapılan tanımlamalar gereği eniyi çözüme ait amaç fonksiyonu değerinin önceden bilinmesidir. Bu özellik sayesinde amaç fonksiyonu değeri kaliteli bir üst sınır olarak kullanılmakta ve çözüm süresi ciddi şekilde azaltılmaktadır. Ayrıca alternatif çözümler bulunarak elde edilebilecek farklı sektörizasyon planlarının karşılaştırılması mümkün olmaktadır. Bunların yanı sıra model, eniyi çözümde sektörler arasındaki iş yükü değişkenliğinin de en fazla $\alpha$ kadar olması garantilenmektedir. Modelin kısa sürede çözüm vermesi önemli bir özelliktir çünkü hava sahası dinamik bir yapıdır ve hava sahasındaki iş yükü anlık olarak değișebilmektedir. Karar verici hava sahasındaki sektör sayısını veya değișen işyükü miktarına göre sektör sorumluluk sahalarını değiştirmek isteyebilir. Bu nedenle hızlı çözüm bulabilen bir model kullanmak önemli hale gelmektedir. Öte yandan hava sahasını daha küçük alanlara bölmek düğ̈̈m sayısını arttıracağı için çözüm süresini ciddi olarak etkileyebilir. $\mathrm{Bu}$ sorun çözüm sürecinde araç rotalama problemi için geliştirilmiş herhangi bir klasik veya meta sezgisel algoritmanın kullanılmasıyla çözülebilir. 
Model, hava sahasının coğrafi referans sistemine göre dörtgenlere bölünmüş olmasına dayanarak sektörizasyon yapmaktadır ancak diğer referans sistemleri için veya başka çokgen şekillerden oluşan hava sahası tasarımları için de uygulanabilir. Ayrıca en iyi çözümlerin $\alpha$ parametresine göre duyarlılığı incelenebilir. Ya da söz konusu hava sahası daha küçük dörtgenlere bölünerek daha hassas bir sektörizasyon yapılabilir. $\mathrm{Bu}$ özellikleri nedeniyle geliştirilen model kullanışlıdır. Tüm bu özelliklerin yanında modelin bir zayıf yönü, bazen veri setine bağlı olarak, yönetilebilirliği sağlayamayan sektörizasyonlar verebilmesidir. $\mathrm{Bu}$ durumu engellemek için modele ek kısıtlar yazılabilir ya da diğer alternatif çözümler bulunarak o çözümlere bakılabilir. Bu da ek işlem maliyeti ve zaman kaybı anlamına gelir. Bundan sonraki çalışmalarda problemin araç rotalama için geliştirilmiş sezgisel algoritmalardan biriyle etkin olarak çözümü araştırılıp bunun bir karar destek sistemi halinde yapılandırılması düşünülebilir.

\section{KAYNAKLAR (REFERENCES)}

1. Gianazza D., Forecasting Workload And Airspace Configuration with Neural Networks and Tree Search Methods, Artificial Intelligence, 174 (7), 530-549, 2010.

2. Tang J., Alam S., Lokan C., Abbass H.A., A MultiObjective Approach for Dynamic Airspace Sectorization Using Agent Based and Geometric Models, Transportation Research Part C: Emerging Technologies, 21 (1), 89-121, 2012.

3. Zelinski S., A Comparisonof Algorithm Generated Sectorizations, Air Traffic Control Quarterly, 18 (3), 279, 2010.

4. Trandac H., Duong V., Baptiste P. Optimized Sectorization of Airspace with Constraints, InProc. of 5th Europe/USA ATM R\&D Seminar, 2003.

5. Brinton C.R., Pledgie S., Airspace Partitioning Using Flight Clustering and Computational Geometry, Digital
Avionics Systems Conference, Saint Paul, 3.B.3-13.B.3-10, 2008.

6. Delahaye D., Airspace Sectoring by Evolutionary Computation, Spatial Evolutionary Modeling, New York, 203-233, 2001.

7. Xue M., Airspace Sector Redesign Basedon Voronoi Diagrams, Journal of Aerospace Computing, Information, and Communication, 6 (12), 624-634, 2009.

8. Delahaye D., Alliot, J.M., Schoenauer M., Farges J.L., Genetic Algorithms for Partitioning Airspace, 10th Conference on Artificial Intelligence for Applications, 291-297, San Antonia, 1994.

9. Chen Y., Zhang D., Dynamic Airspace Configuration Method Based on a Weighted Graph Model, Chinese Journal of Aeronautics, 27 (4), 903-912, 2014.

10. Yousefi A., Optimum Airspace Design with Air Traffic Controller Workload-Based Partitioning, Doktora Tezi, George Mason University, Fairfax, 70-124, 2005.

11. Drew M., Analysis of an Optimal Sector Design Method, Digital Avionics Systems Conference, 3.B.4-1 - 3.B.4-10, Saint Paul, 2008.

12. Yaman K., Hava Sahası Sektörizasyon Problemine Yeni Bir Çözüm Yaklaşımı, Doktora Tezi, Anadolu Üniversitesi, Eskişehir, 30-52, 2010.

13. Li J., Wang T., Savai M., Hwang I., Graph-Based Algorithm for Dynamic Airspace Configuration, Journal of Guidance, Control, and Dynamics, 33 (4), 1082-1094, 2010.

14. Düzakın E., Demircioğlu M., Araç Rotalama Problemleri ve Çözüm Yöntemleri, Çukurova Üniversitesi İİBF Dergisi, 12 (9), 68-87, 2009.

15. Toth P., Vigo D., TheVehicle Routing Problem, Society for Industrial and Applied Mathematics, 2001.

16. Kara İ., Laporte G., Bektas T., A Note on the Lifted Miller-Tucker-Zemlin Subtour Elimination Constraints for the Capacitated Vehicle Routing Problem, European Journal of Operational Research, 158 (3), 793-795, 2004. 